\title{
PERANAN PENYULUH PADA PEMELIHARAAN TERNAK BABI LOKAL DI DESA GUMBO KECAMATAN TIOMNERI KABUPATEN LANNY JAYA
}

\author{
Turi Jigibalom, J. A. Malingkas*, F. S. Oley, S. O. B. Lombogia, \\ Fakultas Peternakan Universitas Sam Ratulangi, Manado 95115
}

\begin{abstract}
ABSTRAK
Penelitian bertujuan untuk mengetahui bagaimana karakteristik dan penilaian peternak babi terhadap kegiatan penyuluhan peternakan di desa Gumbo Kecamatan Tiomneri Kabupaten Lanny Jaya.

Peneitian ini telah dilaksanakan sejak 1 Desember 2017 sampai dengan 31 Januari 2018 dengan menggunakan metode survey.

Responden ditentukan secara cacah lengkap terhadap 22 orang peternak babi di desa Gumbo Kecamatan Tiomneri Kabupaten Lanny Jaya. Pendekatan analisis data menggunakan skala Likert.

Kesimpulan penelitian adalah: 1). Penilaian Peternak terhadap peranan penyuluh pertanian sebagai motivator, dinamisator dan fasilitator di desa Gumbo Kecamatan Tiomneri Kabupaten Lanny Jaya sudah optimal atau dengan kata lain peranan penyuluh dalam melakukan tugas-tugasnya adalah sudah baik. 2). Proses adopsi teknologi oleh peternak babi di desa Gumbo Kecamatan Tiomneri Kabupaten Lanny Jaya bervariasi mulai dari responden yang belum mengetahui tentang teknologi peternakan, sudah mencoba dan sudah menerapkan. 3) Peranan penyuluh sebagai motivator dan dinamisator telah berhasil merubah kebiasaan tradisi peternak yang dulunya memelihara ternak dalam satu rumah tempat tinggal mereka (rumah honai)
\end{abstract}

Korespondensi (corresponding author): Email:johanismalingkas56@gmail.com dan kini peternak telah membuat kandang sendiri di luar tempat tinggalnya.

Kata kunci : Peran Penyuluh dan Pemeliharaan Ternak Babi, Gumbo.

\begin{tabular}{lcrr}
\multicolumn{4}{c}{ ABSTRACT } \\
ROLE OF & CATTLE & PIGS \\
COUNSELORS & MAINTENANCE & OF \\
LOCAL DISTRICT IN THE VILLAGE \\
GUMBO TIOMNERI LANNY & JAYA
\end{tabular}

REGENCY. The study aims to determine characteristics and breeders perception toward extension activities in the District Gumbo village Tiomneri Lanny Jaya Regency Research has implemented since December, $1^{\text {th }}$ until January 31 2018 using survey method. Twenty two of pig breeders in the village pig farmers Gumbo Tiomneri District of Lanny Jaya Regency was selected by census as sample of respondents. Data analysis using scale of likert

Study results indicated that breeders perception of the role of agriculture extension agent as a motivator and facilitator in the District Gumbo village Tiomneri Lanny Jaya Regency was already optimal, or in other words the role of extension officers in performing their duties was already good. The process of adoption of technology by pig farmers in the village of the District Gumbo Tiomneri Lanny Jaya Regency was varied from respondents..The role agriculture counselor as a motivator has succeed to change the habits of farmers tradition that used to keep cattle in the house where they live (home honai) but by now farmers have made pig pen outside their house. 
Keywords: Role of Extension agent, pigs, Gumbo..

\section{PENDAHULUAN}

Pembangunan peternakan sebagai bagian integral pembangunan pertanian yang merupakan bagian dari pembangunan nasional bertujuan antara lain untuk meningkatkan pendapatan dan kesejahteraan peternak, tersedianya kesempatan kerja dan berusaha, tercapainya keseimbangan antara pemanfaatan dan pelestarian sumberdaya alam dan genetic ternak (Untung, 2002).

Berdasarkan tujuan pembangunan sub sektor peternakan maka pengembangan usaha peternakan dapat dilaksanakan dengan berbagai komoditi ternak. Salah satu komoditi ternak yang merupakan peluang berusaha bagi beberapa daerah seperti Sumatera Utara, Toraja, Sulawesi Utara, Bali dan Papua adalah usaha peternakan babi. Hal ini disebabkan karena ternak babi merupakan salah satu komoditi ternak yang digunakan pada upacara ritual adat sesuai kebudayaan masyarakat setempat (Bambang, 1995).

Program pembangunan peternakan yang dimaksud merupakan rangkaian upaya perwujudan pembangunan peternakan yang mampu meningkatkan kesejahteraan peternak, agar dapat berjalan lancar membutuhkan adanya kegiatan penyuluhan atau pendidikan tentang pembangunan (Dali, et al., 2017). Penyuluhan sebagai salah satu kegiatan yang dapat menunjang penciptaan pemberdayaan pada masyarakat tani ternak dalam mengelola dan menghasilkan output peternakan yang efektif dan efisien (Ediset dan Anas, 2013).

Usaha peternakan babi lokal di kabupaten Lanny Jaya dan khususnya di Kecamatan Tiomneri, pada umumnya sebagai usaha pokok selain bertani. Sistem pemeliharaan pada umumnya bersifat tradisional, namun masyarakat menganggap ternak babi lokal sebagai salah satu lambang kekayaan, dan berfungsi sebagai sarana upacara adat, mas kawin, alat pembayaran denda dan merupakan warisan orang tua yang bernilai budaya tinggi serta menjadi sumber pendapatan sehingga ternak babi tidak lepas dari kehidupan masyarakat.

Produktivitas ternak babi di Papua masih rendah, hal ini disebabkan rendahnya pengetahuan peternak mengenai teknik budidaya ternak, baik dari segi pakan, perkandangan, seleksi bibit maupun kontrol terhadap penyakit (Austraning, 2000).

Permasalahan di lapangan berkaitan dengan keberadaan peternak yang masih dalam sistem pemeliharaan secara tradisional memerlukan pembinaan pihak 
pemerintah dalam hal ini para penyuluh pertanian lapangan.

Kajian tentang peran penyuluh dalam penyuluhan bagi peternak babi di Desa Gumbo Kecamatan Tiomneri Kabupaten Lanny Jaya perlu dilakukan untuk mengetahui bagaimana karakteristik dan penilaian peternak babi terhadap kegiatan penyuluhan peternakan.

\section{METODE PENELITIAN}

Penelitian ini dilaksanakan di Desa Gumbo Kecamatan Tiomneri Kabupaten Lanny Jaya. Penentuan lokasi penelitian berdasarkan pada desa yang memiliki populasi ternak babi terbanyak. Penelitian dilakukan selama 2 (dua) bulan yaitu bulan Desember 2017 sampai dengan Januari 2018.

Penelitian ini menggunakan metode survei menurut Sugiyono (2010), di mana dilakukan pendekatan secara langsung kepada peternak dengan pertimbangan yaitu: (1) peternak yang memiliki ternak babi sejumlah 22 orang peeternak, dan (2) peternak yang aktif memelihara ternak sehingga mengetahui dan memiliki pandangan secara individu terhadap peran penyuluh.

Definisi operasional variabel yang di ukur: a. Penyuluh Peternakan adalah orang yang melaksanakan tugas sebagai motivator, dinamisator dan fasilitator.

b. Peran sebagai motivator yaitu penyuluh peternakan senantiasa membuat peternak tahu, mau dan mampu menerapkan informasi inovasi yang dianjurkan.

c. Peran sebagai dinamisator yaitu penyuluh peternakan mampu menggerakkan peternak untuk melakukan perubahan dalam berusaha tani/ternak yang lebih maju.

d. Peran sebagai fasilitator yaitu penyuluh peternakan sebagai perantara peternak dengan pihak-pihak yang mendukung perbaikan dan kemajuan usaha tani-ternak seperti lembaga-lembaga penelitian atau perbankan.

e. Karakteristik peternak ialah faktorfaktor yang berasal dari diri peternak yang mempengaruhi yang mempengaruhi peternak dalam mengembangkan usaha peternakan babi.

Untuk mengukur indikator digunakan skala Likert. (Sugiyono, 2010). Skala Likert dengan pengukurannya diberi bobot skor untuk pertanyaan positif dengan respon sangat baik/ sangat berhasil diberikan skor 5, sebaliknya jika respon termasuk kategori tidak baik/ tidak berhasil diberikan skor 1. Skala Likert tersebut adalah sebagai berikut: (i) Sangat baik/ Selalu/ Sangat 
meningkat $=$ Skor 5; (ii) Baik/ Sering $/$ Meningkat = Skor 4; (iii) Cukup baik/ Kadang-kadang $/$ Cukup meningkat $=$ Skor 3; (iv) Kurang baik/ Jarang/ Kurang meningkat $=$ Skor 2; (v) Tidak baik/ Tidak pernah/ Tidak meningkat $=$ Skor 1 .

\section{Analisis Data}

Penentuan skor dihitung berdasarkan hasil skor respon peternak yang didapat dengan cara menjumlahkan skor sesuai dengan jumlah pertanyaan yang ada pada setiap variabel, sub variabel, dan indikator penilaian. Penentuan kategori tanggapan peternak babi di Desa Gumbo Kecamatan Tiomneri ditentukan dengan menggunakan asumsi dasar interval kelas sesuai pedoman Dajan (2004).

Rumus yang digunakan adalah sebagai berikut:

$$
\mathrm{I}=\text { Skor tertinggi-Skor terendah }
$$

Banyaknya kategori

\section{Keterangan}

I

Skor maksimal = Skor tertinggi $\mathrm{X}$

Jumlah Pertanyaan

Skor minimal $=$ Skor terendah $\mathrm{X}$

Jumlah Pertanyaan

Banyak kategori = Jumlah kategori
Hasil perhitungan analisis kategori variabel penelitian dapat lihat pada tabel 1 .

\section{HASIL DAN PEMBAHASAN}

\section{Keadaan Umum Daerah Penelitian}

Kecamatan Tiomneri terletak dalam Kabupaten Lanny Jaya yang terdiri dari 12 desa, yaitu Kuabaga, Millinggame, Mabume, Tabukeker, Argeneri, Ponalo, Tiwa, Timi, Gumbo, Guari, Bonanip dan Kukepana.

Adapun batas Kecamatan adalah sebagai berikut :

Sebelah Utara berbatasan dengan

: Kecamatan Tiom

Sebelah Selatan berbatasan dengan

: Kecamatan Balingga

Sebelah Timur berbatasan dengan

: Kecamatan Malagaineri

Sebelah Barat berbatasan dengan

: Kecamatan Kayuwaga

\section{Karakteristik Responden}

Karakteristik peternak babi di desa Gumbo yaitu bagian pribadi dan melekat dalam diri individu peternak. Karakteristik ini menjadi dasar prilaku seseorang peternak 
Tabel 1. Kategori variabel penelitian

Tanggapan Peternak terhadap Peran Penyuluh

Kategori

\begin{tabular}{cc}
\hline Skor & \\
\hline $63-75$ & Sangat Baik \\
$51-62,9$ & Baik \\
$39-50,9$ & Cukup Baik \\
$27-38,9$ & Kurang Baik \\
$15-26,9$ & Tidak Baik \\
\hline
\end{tabular}

dalam menjalankan usaha ternak babi di desa Gumbo Kecamatan Tiomneri Kabupaten Lanny Jaya.

Karakteristik peternak babi responden di desa Gumbo terdiri atas:

\section{Umur}

Umur merupakan salah satu unsur penting yang menentukan kualitas atau kemampuan peternak dan menentukan keberhasilan memotivasi peternak terhadap kegiatan belajar dalam pelatihan ketrampilan kerja termasuk dalam usaha beternak.

Tabel 2 menunjukkan responden yang berusia $<29$ tahun sebesar 36,36 \%, yang berusia $30-39$ tahun sebesar $13,64 \%$ dan yang berusia > 40 tahun berjumlah $50,00 \%$. Hal ini berarti rata-rata petani peternak di desa Gumbo, Kecamatan Tiomneri Kabupaten Lanny Jaya, berada pada kelompok usia produktif untuk melakukan pekerjaan atau menjalankan usahanya.

\section{Tingkat Pendidikan}

Peternak yang pendidikan formalnya lebih besar akan lebih mudah menerima inovasi serta perubahan dalam hal beternak. Seperti pendapat yang dikemukakan Soekartawi dalam Lestari,W et al (2009), bahwa petani yang berpendidikan tinggi relatif lebih cepat melaksanakan adopsi inovasi. Tingkat pendidikan responden tersaji dalam tabel 3 .

Tabel 3 menunjukkan bahwa sebagian besar peternak lulusan sekolah dasar (SD) sebanyak 15 orang $(68,18 \%)$, lulusan SMP sebanyak 7 orang $(31,82 \%)$. tingkat pendidikan peternak di Desa Gumbo masih tergolong rendah.

\section{Jumlah Kepemilikan Ternak}

Klasifikasi ternak babi yang dipelihara oleh responden dapat dilihat pada 
Tabel 2. Distribusi Responden Menurut Umur

\begin{tabular}{lccc}
\hline & & \multicolumn{2}{c}{ Peternak } \\
No & Umur Responden (tahun) & Orang & Prosentase \\
\hline 1 & $<29$ & 8 & 36,36 \\
2 & $30-39$ & 3 & 13,64 \\
3 & $>40$ & 11 & 50,00 \\
\hline & Jumlah & 22 & 100 \\
\hline
\end{tabular}

Tabel. 3. Tingkat Pendidikan

\begin{tabular}{llcl}
\hline & & & Jumlah \\
No & Tingkat Pendidikan & Orang & Prosentase \\
\hline 1 & Tingkat Lulusan SD & 15 & 68.18 \\
2 & Tingkat Lulusan SMP & 7 & 31.82 \\
3 & Tingkat Lulusan SMA & - & - \\
4 & Tingkat Lulusan Sarjana & - & - \\
\hline & Jumlah & 22 & 100 \\
\hline
\end{tabular}

Tabel 4.Klasifikasi Responden Berdasarkan Jumlah Kepemilikan Ternak Babi

\begin{tabular}{cccc}
\hline No & Jumlah kepemilikan Ternak & Jumlah Responden & Persentase (\%) \\
\hline 1 & 1-5 Ekor & 16 & 72.72 \\
2 & 6-10 Ekor & 5 & 22.72 \\
3 & >11 Ekor & 1 & 4.55 \\
\hline & Jumlah & 22 & 100 \\
\hline
\end{tabular}

tabel berikut. Jumlah kepemilikan ternak

babi dapat dilihat pada tabel 4 .

Tabel 4 menunjukan klasifikasi pemilikan ternak babi adalah jumlah peternak yang memiliki 1-5 ekor sebanyak 16 ( 72,72\%),yang memiliki 6-10 ekor sebanyak 5 peternak $(22,72 \%)$ dan peternak yang memiliki >11 ekor berjumlah 1 peternak $(4,55 \%)$.
Penyuluh Pertanian Sebagai Motivator, Dinamisator dan Fasilitator.

Peran penyuluh, kinerja penyuluh dan inovasi penyuluh berpengaruh secara langsung terhadap keberdayaan peternak (Rahmawati, et al., 2015). Penyuluhan pertanian merupakan agen perubahan yang langsung berhubungan dengan petani/peternak. Fungsi utamanya yaitu 
Tabel 5. Rekapitulasi Penilaian Peternak Terhadap Peran Penyuluh Sebagai Motivator, Dinamisator dan Fasilitator

\begin{tabular}{lccc}
\hline & \multicolumn{3}{c}{ Peran Penyuluh } \\
Penilaian Peternak & Motivator & Dinamisator & Fasilitator \\
& $\%$ & $\%$ & $\%$ \\
\hline Sangat Baik & - & - & - \\
Baik & 54.55 & 72.73 & 45.46 \\
Cukup Baik & 45.45 & 18.18 & 36.36 \\
Kurang Baik & - & 9.09 & 18.18 \\
\hline
\end{tabular}

mengubah perilaku petani dengan pendidikan non formal sehingga petani mempunyai kehidupan yang lebih baik secara keseluruhan (Sundari, et al., 2015).

Berdasarkan Tabel 5 peran penyuluh oleh petani/peternak babi dapat dikategorikan sebagian besar termasuk dalam kategori baik $(54,557 \%, 72,73 \%$ dan 45,46 ), artinya bahwa peran penyuluh sebagai motivator, dinamisator dan fasilitator telah dijalankan dengan cukup baik dalam menjelaskan, mengarahkan dan mengubah perilaku peternak agar tahu, mau dan mampu menerapkan inovasi. Peran sebagai motivator dikategorikan baik $(54,55 \%)$ dalam memberikan motivasi, pemberian kesempatan bertanya, penyampaian materi dengan jelas dan mudah dipahami, mampu menjelaskan materi dan manfaat beternak babi. Peran sebagai dinamisator yang dikategorikan baik $(72,73 \%)$ dalam mendorong pertemuan berkala dan kesedian untuk menemui dan ditemui peternak. Sebagai fasilitator penyuluh menjalankan dengan baik $(45,46 \%)$, hal tersebut dilihat dari kesediaan saling bertemu antara penyuluh dan peternak dan mendorong pertemuan berkala sebagai bentuk mempercepat adopsi inovasi. Namun, dalam hal kerjasama dengan pihak Dinas Peternakan setempat dan Swasta dalam memberikan penyuluhan masih belum dilakukan secara maksimal.

Penyuluh sebagai fasilitator merupakan peran dalam mendukung terselenggaranya proses pembelajaran peternak dengan baik (Yunasaf dan Tasripin, 2011). Kajian ini seirama dengan hasil penelitian Lamarang, et al., (2017) bahwa peran penyuluh terhadap pengambilan keputusan peternak telah dilaksanakan dengan baik.

Menurut Mardikanto (1993) bahwa penyuluhan merupakan suatu sistem 
pendidikan non formal yang tidak sekedar memberikan penerangan atau menjelaskan, tetapi berupaya merubah perilaku sasarannya. Kegiatan penyuluhan yang bertujuan merubah perilaku sasarannya tidak terlepas dari peran penyuluh dalam menjalankan tugas sesuai dengan peran sebagai pendidik, fasilitator dan katalisator (Utami dan Sita, 2018).

\section{KESIMPULAN DAN SARAN}

Penilaian Peternak terhadap peranan penyuluh pertanian sebagai motivator, dinamisator dan fasilitator di desa Gumbo Kecamatan Tiomneri Kabupaten Lanny Jaya yaitu sudah optimal atau dengan kata lain peranan penyuluh dalam melakukan tugastugasnya adalah sudah baik.

Proses adopsi peternak babi di desa Gumbo Kecamatan Tiomneri Kabupaten Lanny Jaya adalah bervariasi mulai dari responden yang belum mengetahui tentang teknologi peternakan, sudah mencoba dan sudah menerapkan.

Peranan penyuluh sebagai motivator dan dinamisator telah berhasil merubah kebiasaan tradisi peternak yang dulunya memelihara ternak dalam satu rumah tempat tinggal mereka (rumah honai) dan kini peternak telah membuat kandang sendiri di luar tempat tinggalnya.

\section{Saran}

Peranan penyuluh sebagai fasilitator perlu dikembangkan ke depan agar dapat membantu petani peternak babi di desa Gumbo dalam pengembangan usaha melalui dukungan fasilitas kredit pihak perbankan.

\section{DAFTAR PUSTAKA}

Austraning Nusantara, 2000. Master PlanKawasan Sentra Produksi (KSP) Provinsi Irian Jaya. Kerjasama dengan Pemerintah Daerah Tk. I Irian Jaya.

Bambang, S. 1995. Ternak Komersial. Penebar Swadaya. Jakarta.

Dajan, A. 2004. Pengantar Metode Statistik Jilid II. Jakarta:LP3ES.

Ediset dan A. Anas. 2013. Peranan penyuluh dalam penerapan paket teknologi pada usaha peternakan kerbau (Studi Kasus Pada Kelompok Ternak "Kerbau Antrada" Kecamatan Koto Baru Kabupaten Dharmasraya). Jurnal Peternakan Indonesia Vol 15(1): 17-25.

Dali. I., F S. Oley, A.K.Rintjap dan J M.Tumewu.2017. Hubungan kinerja penyuluh pertanian lapangan dengan keberhasilan peternak sapi potong di Kecamatan Kwandang Kabupaten Grontalo Utara. Jurnal Zootek Vol 37(2):403-414. 
Lestari W, S Hadi, N.Indris, dan Z. Lamarang. 2009. Tingkat adopsi inovasi peternak dalam beternak ayam broiler di Kecamatan Bajubang Kabupaten Batang Hari.Jurnal Ilmiah Ilmu-ilmu Peternakan, Jurnal ilmu ilmu Peternakan 12 (1) : 15-17

Mardikanto, T. 1993. Penyuluhan Pembangunan Pertanian. Sebelas Maret University Press, Surakarta.

Rahmawati, I.R, Muksin dan Rizal. 2015. Peran dan kinerja penyuluh pertanian dalam memberdayakan peternaka ayam petelur di Kabupaten Jember. Jurnal Ilmiah Inovasi . 15 (3): 56-63.

Sugiyono,2010. Metode Penelitian Kuantitatif Kualitatif Dan R\&D. Bandung Alfabeta.

Sundari, A.A Hamid, Yusra dan Nurliza. 2015. Peran penyuluh pertanian terhadap peningkatan produksi uahatani di Kabupaten Pontianak. Jurnal Social Economic of Agriculture 4(1): 26-31.

Untung, S. 2002. Strategi Dan Kebijakan Pengembangan Agribisnis Peternakan Dalam Rangka Otonomi Daerah Dan Perdagangan Internasional, Dinas Peternakan Sulawesi Utara. Manado.

Utami, S.N dan S.K. Sita. 2018. Peran Komunikasi penyuluh lapangan dalam pembangunan agribisnis ternak itik di Kabupaten Brebes. Jurnal Peternakan Indonesia 20 (3): 160165.

Lamarang. Z., B.F.J.Sondakh, A K.Rintjap dan A.A.Sajow.2017. Peranan penyuluh terhadap pengambilan keputusan peternak dalam adopsi inovasi teknologi peternakan Di Kecamatan Sangkup Kabupaten Bolaang Mongondow Utara. Jurnal Zootek 37(2):496-507. 
